\title{
Communication Characteristics of Young Children with HIV in South Africa as reported by Some Physicians.
}

\author{
Michelle Hattam ${ }^{1 *}$, Brenda Louw ${ }^{2}$ and Salome Geertsema ${ }^{3}$ \\ ${ }^{1}$ Con Amore School, Sable Street, Esther Park, Kempton Park, South Africa \\ ${ }^{2}$ Department of Audiology and Speech-Language Pathology, East Tennessee State University, \\ Johnson City, Tennessee, United States \\ ${ }^{3}$ Communication Pathology, University of Pretoria, Lynnwood Road, Pretoria, South Africa \\ * Corresponding author, email: mich.hattam@gmail.com
}

\begin{abstract}
HIV (Human Immunodeficiency Virus) has been shown to have significant effects on the development of a child. Currently there is limited South African research regarding HIV and specific characteristics of communication development, and the treatment thereof, in the child infected with HIV. The objective of the research was to describe the communication characteristics of a group of children between the ages of $0-5$ years infected with HIV at a hospital in Gauteng, South Africa. Clinic records of 203 children infected with HIV between the ages of 0-5 years were reviewed by using a pre-designed checklist within the outreach clinic of a large regional hospital.
\end{abstract} A questionnaire was completed by 4 medical practitioners working with this population within the outreach clinic. A total of $91.62 \%$ of the infected children were diagnosed as being either in Stage III or IV of the disease (according to the WHO classification system of 2005), with all infants presenting with a CD4 count of $\leq 60$. The majority (75.37\% of the total sample) were receiving HAART (Highly Active Antiretroviral Therapy) at the time the data was collected. According to their medical, social, communication and general development, almost all the children qualified for Early Communication Intervention (ECI) but were not recorded as being referred for such services. A large proportion of the target population presented with opportunistic infections and/or HIV associated conditions. The results highlight the developmental characteristics of children living with HIV, and identify the need for medical doctors and allied health professionals to be provided with relevant literature or training regarding the communication development of children infected with HIV. This will facilitate appropriate referrals for $\mathrm{ECl}$ services. 
Keywords: Early Communication Intervention (ECI), Highly Active Antiretroviral Therapy (HAART), Human Immunodeficiency Virus (HIV), opportunistic infections, speech-language therapist and audiologist

\section{Introduction}

Children are severely affected by the global HIV epidemic, nowhere more so than in sub-Saharan Africa, the region that carries the brunt of the HIV disease burden (Marais, Kangwana, Rabie \& Cotton, 2007) These vulnerable children experience rapid disease progression with more than $30 \%$ mortality during the first year of life (Van Dyk, 2005). The clinical course of HIV infection in children differs significantly from that in adults. The timely initiation of Highly Active Antiretroviral Therapy (HAART) does prevent severe opportunistic infections associated with WHO (2005) stage IV disease, and is viewed to be part of appropriate basic care (Rabie, Marais, Van Toorn, Nourse, Nel, Goussard, et al., 2007b). Even with the implementation of such care, children with HIV fall into the established-risk category for communication delay (Rossetti, 2001). The term Early Intervention (EI) refers to services provided to very young children with special needs, beginning as early as possible, preferably from birth. $\mathrm{ECl}$ is the provision of intervention to children at-risk or with established risk for abnormal or delayed communication development. Due to the myriad of developmental, communication and social delays/disorders that may affect the young child infected with HIV, $(E C I)$ is essential to reduce delayed and disordered developmental patterns in the paediatric HIV population and to improve the quality of these children's lives (McNeilly, 2000). The speech-language therapist and audiologist are vital to the team approach in working with children HIV in hospitals, school, and other contexts (Rossetti, 2001).

$\mathrm{ECl}$ services are required to be comprehensive, coordinated, and team based, according to the highest quality evidence available (ASHA, 2008). Teamwork provides the best standard of care when assessing and treating the paediatric HIV population. However, a dearth of literature describing the developmental characteristics of the paediatric HIV population exists (Swanepoel \& Louw, 2010). Speech-language therapists and audiologists working with children with HIV currently have no researched-based protocols to guide the assessment and 
intervention process, impacting international standards of best practice. Rossetti (2001) emphasised the importance of early intervention with this vulnerable population. The implication is that once delays or disorders in development in children with HIV have been identified, children below the age of 3 years should be enrolled in an appropriate early intervention program initiated by the speechlanguage therapist and audiologist as soon as possible. The ideal suggested schedule for assessment of children with HIV includes developmental evaluation by 2 months of age, with follow ups every 6 months for the first 2 years of life. However, this plan may be challenged by the age of diagnosis and the availability of services (Rossetti, 2001).

The objective of the study was to describe the medical and communication characteristics of the HIV infected children being seen at the outreach clinic of a regional hospital, in an attempt to contribute to the knowledge base of the South African paediatric HIV population. Such information will serve as background information to the development of research based assessment and intervention protocols for paediatric HIV communication intervention in the future.

\section{Methods}

The main objective was to describe the characteristics of a group of children between the ages of 0-5 years infected with HIV (as noted in their clinic records) at a large regional hospital in Gauteng, South Africa. The researchers sought to determine the prevalence of children infected with HIV within the caseload, and to describe the current medical conditions of these children. Other objectives were to determine the presence and nature of communication disorders in this population, and to explore the current practices surrounding team assessment and intervention of the HIV infected population within the specific hospital setting. Lastly the perceptions and practices of medical doctors involved in the treatment of this paediatric HIV population were explored.

A cross-sectional non-experimental, descriptive and quantitative research design was utilised. This allowed for a wide age range (0-5 years) to be sampled and compared. The use of both a checklist and questionnaire in the study facilitated evaluation and quantification of the paediatric HIV population at the hospital. 
The hospital includes an outreach clinic to which infants with suspected and confirmed HIV diagnoses are referred to from both the paediatric in- and outpatient departments. Permission to conduct the study was obtained from the hospital Chief Executive Officer (CEO) as well as from the Gauteng Department of Health. Ethics clearance was granted by the Research Ethics and Proposal Committee, Faculty of Humanities, University of Pretoria, South Africa. Informed consent was obtained from the medical practitioners who acted as respondents prior to completing the questionnaire. Since clinical records of children were used for data collection, and the records were referred to by a code, parental consent was not deemed to be necessary.

The clinic records of 203 children infected with HIV between the ages of 0-5 years 11 months were selected for data collection, with a relatively even gender distribution of 113 male and 90 female children. Children had to be diagnosed and confirmed as HIV positive by both the ELISA (The enzyme-linked immunosorbent assay test) and PCR (Polymerase chain reaction test) methods as proposed by the National Department of Health and not based exclusively on clinical presentation. At the time the study was conducted in 2010, 7 medical practitioners treating the hospital's paediatric population were practicing within the outreach clinic and 4 agreed to participate as respondents in the study.

A checklist (Appendix 1) was developed for data collection from the clinic records based on locally relevant literature regarding the paediatric HIV population's medical characteristics (Marais, Hesseling, Gie, Schaaf \& Beyers, 2006; Marais, Rabie, Schaaf \& Cotton, 2006; Marais, Rabie Van Toorn, Nel, \& Cotton, 2006; see Appendix 2) as well as from international and local literature regarding social, communicative and developmental characteristics of children infected with HIV. A questionnaire was compiled to survey the medical practitioners' perceptions and practices regarding the general and communicative development of the paediatric HIV population within the clinic. The checklist and questionnaire were piloted and revised before the main study.

The clinic records of 517 children below the age of 18 years of age within the outreach clinic were accessed, of which 203 were identified to be those of children 
infected with HIV between the ages of birth to 5 years 11 months. The checklist was used to manually record the predetermined data from the clinic files of the 203 infants that matched the criteria for inclusion. The questionnaire (Appendix 3) was distributed to the medical practitioners practicing at the outreach clinic who served as respondents. Contact was maintained and questionnaires were collected at a time convenient for both the respondent and the researcher.

Once data recorded from the completed checklists had been captured and entered into a Microsoft excel data sheet, a statistical analysis through the use of a statistical analysis system (SAS) was performed. SAS allowed the researcher to describe the characteristics of the paediatric HIV infected children within the outreach clinic from the results obtained from the data collection process in an outlined, detailed fashion (Cabrera \& McDougall, 2002). The PROC FREQ data generated by SAS provided a frequency count of the values each variable represented of the total data and allowed for a description of the characteristics of a group of children infected with HIV. A frequency value was provided for each characteristic recorded from the child's hospital record, as well as the percentage of the total sample size this represented.

\section{Results and Discussion}

The results presented are part of a larger study. The most pertinent results were selected as space constraints did not allow for reporting all the results of the data gathered by reviewing the records and from the questionnaire.

Prevalence of children infected with HIV: The study was conducted in 2010. Of 1356 patients, 517 were from children below 18 years of age. A total of $153(75 \%)$ of the HIV infected children were receiving HAART. Of the 50 children not yet on treatment, 25 were in the preparatory phase and 25 had not yet met treatment initiation criteria (WHO, 2005) 


\begin{tabular}{|l|c|c|}
\hline \multicolumn{1}{|c|}{ Associated Condition } & Number of subjects & Percentage \\
\hline Static Encephalopathy & 13 & 19 \\
\hline LIP (Lymphoid interstitial pneumonitis) & 8 & 11 \\
\hline Bronchietasis & 4 & 6 \\
\hline Progressive Encephalopathy & 2 & 4 \\
\hline Seizures & 1 & 2 \\
\hline FTT (Failure to Thrive) & 40 & 58 \\
\hline
\end{tabular}

Medical characteristics: The World Health Organization (WHO) published a new four stage paediatric clinical staging system in 2005 (Appendix 2). This system takes into consideration frequently observed problems facing clinicians in the developing world. The staging system differentiates conditions where a presumptive diagnosis can be made on the basis of clinical signs or simple investigations, from those where confirmatory testing is required. The creation of four stages provides the additional advantage of synchronizing paediatric and adult staging systems, resulting in less confusion for healthcare workers and allowing an easier transition from paediatric to adult care (Rabie et.al, 2006: 56). As mentioned above, a total of 153 of the 203 children infected with HIV at the outreach clinic were receiving HAART at the time the data was collected. Of these, 5 were in Stage II, 120 children were in Stage III and a further 28 were in Stage IV as is referenced in Table 1. The 25 children who were not receiving treatment likely did not yet qualify for treatment according to clinical and immunological staging (WHO, 2005). A further 25 children where treatment initiation was pending, were likely in the process of treatment preparation, as the outreach clinic necessitates parents/caregivers to attend at least 3 counseling sessions before initiating HAART. Specific drug regimens were not recorded, which is a limitation of the study. Some drugs, e.g. Ziduvudine Didanosine, have been proven to cause permanent sensorineural hearing loss in the paediatric population (Swanepoel \& Stearn, 2010, in Swanepoel \& Louw, 2010). Hearing loss is one of the causes of speech and language delay, and such ototoxic drugs may have far reaching negative effects on the communication development of children. However, the value of HAART is that ARV's from different classes are combined to achieve maximum and prolonged suppression of viral replication, which has brought about a significant reduction in the morbidity and mortality associated with paediatric HIV (Rabie, Marais \& Cotton, 2006b). This is also likely to have a positive impact on the 
children's communication development, as their general health improves, allowing for increased social interaction and communication. According to Phuthanakit et al. (2013), no differentiation between early versus deferred HAART in older children was noted. However, Shanbhag et al. (2005) showed that combination antiretroviral therapy is associated with improved neurocognitive outcomes in children with perinatally acquired HIV infection. Early intervention services with the HIV infected allows for improved developmental outcomes (Rossetti, 2001).

A total of 13 cases of static encephalopathy and 2 of progressive encephalopathy were noted. Therefore, at least 15 children from the current study qualified for $\mathrm{ECI}$ services, due to the presence of static or progressive encephalopathy. According to the American Academy of Neurology AIDS Task Force, failure to develop or the loss of previously developed intellectual functions such as receptive and expressive language is one of the indications for the diagnosis of encephalopathy in children (Rabie et al., 2007).

Failure to Thrive (FTT) was a presenting feature in 40 of the children in the current study, which is an anticipated finding. FTT is a major predictor for death in HIV infected children, and should be considered for a classification system of disease severity in African children (Van Kooten Niekerk, Knies, Howard, Rabie, Zeier, van Rensburg, et al., 2005). FTT, together with weight loss, may be due to the direct effect of the virus on the child's gastrointestinal tract, secondary opportunistic infections or poor nutritional intake (Van Dyk, 2005). Recurrent oral candidiasis may also further contribute to FTT in this population.

Table 2: Primary Caregivers of HIV infected children $(n=203)$

\begin{tabular}{|l|c|c|}
\hline \multicolumn{1}{|c|}{ Caregiver } & Number of Subjects & Percentage \\
\hline Mother & 110 & 54 \\
\hline Father & 2 & 5 \\
\hline Both Parents & 12 & 26 \\
\hline Extended Family & 53 & 3 \\
\hline Both Parents and Extended Family & 4 & 11 \\
\hline Mother and Extended Family & 22 & 1 \\
\hline
\end{tabular}


Social aspects: Table 2 illustrates that a total of 110 (54\%) of the children infected with HIV at the outreach clinic were in the care of their mother (as a single parent), with no other adult family member residing in the same home. A total of $53(26 \%)$ children were in the care of their extended family alone and not in the care of either biological parent. This reflects the social impact of HIV within the South African context, as the number of HIV orphans increases (Mamaila, 2005).This finding verifies the results of Van Kooten Niekerk et al. (2005) who found mothers as primary caregivers were by far in the majority. Many children acquire HIV through vertical transmission; implying that most mothers will themselves be infected with HIV. With the likelihood of reduced maternal health, the mothers as primary caregivers increasingly have to depend on the other resources and their parenting is compromised. Children infected with HIV therefore also have environmental risk factors such as limited stimulation and communicative interaction, and multiple caregivers, that may impact on their general and communicative development.

\section{Communication disorders and associated conditions:}

Table 3: Presence of associated factors affecting communication development in HIV infected children $(n=39)$

\begin{tabular}{|l|c|c|}
\hline \multicolumn{1}{|c|}{ Associated Factor } & Number of Subjects & Percentage \\
\hline Developmental Delay & 17 & 43 \\
\hline Acute Otitis Media with Effusion & 12 & 30 \\
\hline Chronic Otitis Media & 7 & 17 \\
\hline Acute Otitis Media without Effusion & 3 & 10 \\
\hline
\end{tabular}

Information regarding the speech production and speech development of children infected with HIV being managed at the outreach clinic was not well documented in the children's hospital records. However, the records of 5 children, between the ages of 16 and 27 months, indicated they were on a single word level. These children were in the prelinguistic and early stages of linguistic development (Rossetti, 2001). No other data regarding the development of speech and language in the paediatric HIV population was documented in the children's hospital records. It was determined that one infant was referred for speech-language therapy and/or audiological 
assessment and intervention. It is possible that many of the children managed in the outreach clinic presented with delayed and/or disordered speech and language development. It is unclear whether other children in the outreach clinic were indeed referred for speech-language therapy and/or audiological services or whether the referrals were just not documented. Results obtained regarding the medical characteristics of the children infected with HIV in this study clearly indicate the high risk for communication delays and disorders of this population (refer to Table 1). Layton and Hao (2010, in Swanepoel \& Louw, 2010) discuss the effects that HIV infection has on communication development and functioning, and the importance of early identification and referral for intervention services. Although there is a dearth of information on the early communication development of infants with HIV within the local setting, McFarland (2000) describes many of the symptoms regarding the nature and character of language compromises in the HIVIAIDS infected child. One of the characteristics of paediatric HIVIAIDS infection is central nervous system (CNS) dysfunction resulting from encephalopathy. This causes muscle tone abnormalities that may compromise oral-motor development or result in loss of oralmotor developmental milestones McFarland (2000). International research documents delays in receptive and expressive language aspects of linguistic functioning for HIVIAIDS infected children, where delays in expressive language development are reported more so than in receptive language development (Screen \& Lee-Wilkerson, 2007).

As mentioned earlier, one infant infected with HIV being managed at the outreach clinic was referred for speech-language therapy and/or audiological assessment and intervention. However, no detail was provided in the chart regarding the reason for or the expectations of the referral. This again raises the issue of whether referrals were made but not noted in the records, or were not made at all. Results obtained regarding the medical characteristics of the children infected with HIV in this study clearly indicate the high risk for delay and disorder in the communication development of this population.

Children with HIV fall into the established-risk category for communication delay (Rossetti, 2001). This implies that children infected with HIV are expected to present with delays in acquiring communicative milestones to some degree. Children in the 
established-risk category may display developmental delay secondary to the main medical disorder/infection present (Rossetti, 2001). Thus, children with HIV may present with delays and/or disorders in several developmental areas such as motor, speech, language and cognitive development when compared to neurotypical children, due to the presence of the HIV as an underlying cause. Results indicated that 17 children presented with a developmental delay. However, as 175 of the children were recorded to be in Stage III and Stage IV disease progression with low CD4 count, it is speculated that a much larger number may have been developmentally delayed. Developmental delays are present in the majority of symptomatic children infected with HIV, with reports of involvement ranging from 60 to $90 \%$ of children (McNeilly, 2005). It is not clear whether the children indeed did not present with developmental delay, or whether no record was made regarding the developmental status of the remaining 186 children within the total sample, even if developmental delay was a presenting characteristic.

A total of 12 cases of acute otitis media with effusion, and 2 cases of acute otitis media without effusion, were documented. A further 8 cases of chronic otitis media were recorded in the hospital records of the children infected with HIV being managed at the outreach clinic. Otitis media with risk for hearing loss is a frequent manifestation of HIV infection (Gold \& Tami, 1998). According to McNeilly (2005), conductive hearing losses seen in $50 \%$ of infants and children infected with HIV, and $5 \%$ have severe to profound sensorineural hearing losses. As pointed out earlier, some drugs are also known to be ototoxic and place children at risk for sensorineural hearing loss (Swanepoel \& Stearn, 2010, in Swanepoel \& Louw, 2010). It is therefore likely that a significant percentage of children infected with HIV in this study would have presented with hearing loss. However, no information regarding the presence of hearing loss, or suspected hearing loss, or referrals for a hearing evaluation, was recorded.

Feeding difficulties: Feeding disorders are characteristic of children infected with HIV, such as nasopharyngeal incoordination, which is an important pointer to neurological involvement (Rabie, Marais, Van Toorn, Nel, \& Cotton, 2007a). However, in contrast to the research, no information regarding swallowing and/or feeding was reported in the hospital records of the children infected with HIV, nor 
was the presence of a swallowing/feeding disorders documented. It is unclear whether feeding and/or swallowing were screened specifically by medical doctors during the child infected with HIV's initial and/or follow-up visits, or whether the focus was on their nutritional status only. The presence of feeding and/or swallowing disorders in the paediatric HIV population necessitates the services of the speechlanguage therapist (McNeilly, 2005; Rabie et al., 2007a). It is likely that feeding and/or swallowing difficulties indeed did occur in the paediatric HIV population being treated at the outreach clinic, and that these children did not receive the necessary speech-language therapy assessment and intervention services they require.

The finding that $96 \%$ (194) of the children were referred to a dietician and social worker for further management, indicates that there may well have been feeding and swallowing issues present in the children, since feeding and swallowing disorders automatically affect their nutritional status. The specific reason for referral was, however, not documented (this may have been due to their FTT although this is unclear). The medical practitioners may not have been aware of role that the speech-language therapist plays in these disorders. Furthermore the fact that the outreach clinic had a full time dietician and social worker employed at the time the data was collected, may have explained the high number of referrals. The vast majority of children were receiving nutritional support as well as assessment and management of social aspects within the clinic. Children depend on parents and/or caregivers to bring them to the outreach clinic, as well as administer and manage their medication. A stable social environment and the identification of a reliable caregiver are therefore essential (Rabie, Marais \& Cotton, 2006b). Malnutrition is common in many HIV infected children, particularly those under 2 years of age (Van Kooten Niekerk et al., 2005). It is therefore imperative that children infected with HIV receive nutritional management in order to optimise their nutritional status.

Team approach: With 13 children presenting with progressive encephalopathy and two children with static encephalopathy (Table 1), the need for physiotherapy and occupational therapy services to this population is highlighted. As before, it is unclear whether further children infected with HIV, that were being managed at the outreach clinic, were referred for physiotherapy and occupational therapy services and that this was merely not documented in their hospital files, or whether these referrals 
were indeed not made. It is clear that there was a referral system in place in the outreach clinic, but that not all professional disciplines available within the hospital setting were being utilised. A multidisciplinary approach to $\mathrm{ECl}$ is essential when working with children infected with HIV (Rossetti, 2001). The speech-language therapist and audiologist have a key role to play within the team due to the high risk for communication disorders and delays and the importance of communication skills in a child's quality of life.

Perceptions of medical practitioners: The respondents perceived general developmental delay within the paediatric population as the main disorder present in children infected with HIV, yet only $17(8.37 \%)$ of the total children sampled were documented as having general developmental delay. All the respondents were of the opinion that doctors are not always aware of the implications of not referring children infected with HIV for early assessments of communication, swallowing, cognitive development, and hearing testing. Respondents appeared to be aware of the possible presence of delays in language and cognitive development in the HIV infected population. It remains unclear why such low rates of speech, language, and cognitive delays and/or disorders were documented in the hospital records of those children infected with HIV, who were being managed at the outreach clinic.

The reason for the low referral rate to speech-language therapists and $\mathrm{s}$ audiologists, as documented in the study, is also unclear. Furthermore it is speculated that South African medical practitioners in general, are not cognisant of the important role that the speech-language therapist and audiologist have in the assessment and treatment of the HIV infected child, as well as their role within the interdisciplinary team.

\section{Conclusions}

The current study described the characteristics of a group of children infected with HIV who were being managed at an outreach clinic within a regional hospital in Gauteng, South Africa, as well as the perceptions of the medical practitioners treating them. Results indicated that several children infected with HIV who were being treated at the outreach clinic at the time this study was conducted, presented 
with opportunistic infections and/or HIV associated conditions. These infections place children at risk for communication disorders and delays, implying that $\mathrm{ECl}$ services would be appropriate to facilitate development and ameliorate the impact of the virus.

The predominant finding was that very few children in the study were recorded as presenting with delays and/or disorders in speech, language and hearing, contrary to literature findings. By implication, several children infected with HIV were not provided with the essential ECI services as they were not identified as candidates for assessment and intervention by the speech-language therapist and audiologist (Rossetti, 2001). It is not clear whether these children, according to the medical practitioners treating them within the outreach clinic, indeed did not present with delays and/or disorders in communication, or whether they were identified as candidates for $\mathrm{ECl}$ services but this was not recorded in their clinic records. With reference to research findings on HIV (e.g. McFarland, 2000; McNeilly, 2000, 2005), it is assumed that these delays and disorders were most likely present but were either not identified or not indicated in the clinic records. It is the responsibility of the speech-language therapist and audiologist working within the clinical setting to promote $\mathrm{ECl}$ services for infants and children affected with HIV within the multidisciplinary team as well as educating the team members regarding the developmental characteristics of this population.

Results further highlight the need for the speech-language therapist and audiologist to play an active role in the team approach to the management and care of children infected with HIV being treated at outreach clinics (McNeilly, 2005). Where resources allow, $\mathrm{ECl}$ assessment and intervention services should ideally be carried out within the service providing clinic itself, and all children infected with HIV and their families and caregivers should be provided with ongoing $\mathrm{ECl}$ services parallel to medical care and management. The suggested schedule for assessment according to international literature includes developmental evaluation by two months of age, with follow ups at least every six months for the first two years of life. After two years of age, children should be re-evaluated at least yearly if they remain asymptomatic (Rossetti, 2001). 
It is likely that not all medical practitioners working with children infected with HIV are aware of the impact paediatric HIV may have on communication development. They may also not be familiar with the role of the speech-language therapist and audiologist in the assessment and treatment of the child infected with HIV, which may explain the low referral rates to the speech-language therapist and audiologist by the medical practitioners who participated in the study. As the results show, the records often contained limited information. This could be explained by a variety of factors such as restricted time and administrative support, and a lack of in-depth knowledge regarding the characteristics of children with HIV. A comprehensive team approach to treating children with HIV needs to emphasize the importance of accurate documentation by all members and especially the medical practitioner team members.

Finally, the results from this study identified the need for speech therapists and audiologists to promote their roles in $\mathrm{ECl}$ for children infected with HIV. This can be done by offering in-service and continuing education training opportunities and by disseminating research results to medical practitioners and other team members regarding the cognitive, communication and swallowing development of the child infected with HIV. By emphasizing the importance of early referrals and early intervention, children receiving HAART would be more likely to achieve their developmental milestones in an appropriate manner.

It is recommended that the research design implemented in this study be repeated in other clinical settings within the South African context to allow for a comprehensive description of the characteristics of the pediatric HIV population. This study only allowed for a small sample of children infected with HIV to be targeted and therefore results cannot be generalized to the larger population (Leedy \& Ormrod, 2005). A larger sample of medical practitioners would also have yielded stronger results. Further research could implement a longitudinal study, allowing for more comprehensive data regarding the characteristics of the pediatric HIV population within South Africa. Optimal ECl service delivery to the paediatric HIV population in South Africa and abroad can only be achieved by the ongoing clinical research within the profession of speech-language therapy and audiology and an interdisciplinary 
team approach, which would ensure best practice and make a difference to the quality of these children's lives.

\section{References}

ASHA. (2008). 'Roles and Responsibilities of Speech-Language Pathologists in Early Intervention: Position Statement.' http://www.asha.org [11 May 2010].

'Broad Framework for HIV and AIDS and STI Strategic Plan for South Africa 20072011.' (2006). http://www.doh.gov.za/docs/policy/2006/aids/pdf [10 February 2010].

Gold, S., \& Tami, T.A. (1998). Otolaryngological manifestations of HIVIAIDS. Seminars in Hearing 19(2), pp.165-166

Layton, T.L, \& Hao, J (2010). Communication Disorders in Children with HIVIAIDS, in Swanepoel, D.W., \& Louw, B. (2010). HIV/AIDS Related Communication, Hearing and Swallowing Disorders. San Diego, Plural Publishing.

Leedy, P.D., \& Ormrod, J.E. (2005). Practical Research: Planning and Design. (8th Edition). New Jersey, Pearson Merrill Prentice Hall.

Mamaila, T. (2005). Community-based care for HIVIAIDS orphans. Unpublished M Social Development and Policy research study.

Marais, B.J., Hesseling, A.C., Gie, R.P., Schaaf, H.S., \& Beyers, N. (2006a). The burden of childhood tuberculosis and the accuracy of routine surveillance data in a high-burden setting. International Journal of Tuberculosis and Lung Disease 10, pp. 259-263.

Marais, B.J., Rabie, H., Schaaf, S.H., \& Cotton, M.F. (2006b). Common opportunistic infections in HIV infected infants and children, Part 1-Respiratory Infections. South African Family Practice 48, pp. 52-56. 
Marais, B.J., Rabie, H., Van Toorn, R., Nel, E.D., \& Cotton, M.F. (2006c). Common opportunistic infections in HIV infected infants and children, Part 2-non-respiratory infections. South African Family Practice. 49, pp. 40-45.

Marais, B.J., Kangwana, B.B., Rabie, H., \& Cotton, M.F. (2007). Caring for our children. South African Family Practice 49(4), p. 1.

McFarland, E.D. (2000). Language and oral-motor development and disorders in infants and young toddlers with Human Immunodeficiency Virus. Seminars in Speech and Language 21, pp. 7-33.

McNeilly, L.G. (2000). Communication intervention and therapeutic issues in paediatric HIV. Seminars in Speech and Language 21, pp. 63-77.

McNeilly, L.G. (2005). HIV and Communication. Journal of Communication Disorders 38, pp. 303-310.

Phuthanakit, T., Ananworanich, J., Vonthanak, S., Kosalaraksa, P., Hansudewechakul, R., van der Lugt, J., Kerr, S., Kanjanavanit, S., Ngampiyaskul, C., Wongsawat, J., Luesomboon, W., Vibol, U., Pruksakaew, K., Suwarnlerk, T., Apornpong, T., Ratanailok, K., Paul, R., Mofeson, L., Fox, L., Valcour, V., Brouwers, P., \& Xrungtham, K. (2013). Cognitive function and neurodevelopmental outcomes in HIV-infected children older than 1 year of age randomized to early versus deferred antiretroviral therapy: The PREDICT Neurodevelopmental study. Paediatric Infectious Disease Journal: 32 (5): 501-508. doi: 10.1097/INF.0b013e31927fb19d

Rabie, H., Marais, B.J., \& Cotton, M.F. (2006a). Preventing and diagnosing HIV infection in infants and children. South African Family Practice 48(6), pp. 34-41.

Rabie, H., Marais, B.J., \& Cotton, M.F. (2006b). Initiating anti-retroviral therapy in HIV-infected infants and children. South African Family Practice 48(7), pp. 54-58. 
Rabie, H., Marais, B.J., Van Toorn, R., Nel, E.D., \& Cotton, M.F. (2007a). Common opportunistic Infections in HIV infected infants and children. South African Family Practice 49(2), pp. 40-45.

Rabie H., Marais, B.J., Van Toorn, R., Nourse, P., Nel, E.D., Goussard, P., Sellers, N., \& Cotton, M.F. (2007b). Important HIV-associated conditions in HIV infected infants and children. South African Family Practice 49(4), pp. 19-23.

Rossetti, LM. (2001). Communication Intervention: Birth to Three. (2 ${ }^{\text {nd }}$ Edition). San Diego, Singular Publishing.

SAS Institute Inc. (2008). SAS/STAT® 9.2 User's Guide. Cary, NC:SAS Institute Inc.

Screen, R.M., \& Lee-Wilkerson, D. (2007) HIV, Substance Abuse and Communication Disorders in Children. New York, The Haworth Press.

Shanbhag, M.C, Rutstein, R.M, Zaoutis, T, Zhao, H, Chao, D, Radcliffe, J (2005). Neurocognitive functioning in paediatrics human immunodeficiency virus infection: effect of combined therapy. Archives of paediatrics \& adolescent medicine, Jul; 159 (7):651-656.

Swanepoel, D.W and Louw, B (2010). HIV/AIDS Related Communication, Hearing and Swallowing Disorders. San Diego, Plural Publishing.

Swanepoel, D.W and Stearn, N.A (2010). Sensory and neural auditory disorders associated with HIVIAIDS, in Swanepoel, D.W., \& Louw, B. (2010). HIV/AIDS Related Communication, Hearing and Swallowing Disorders. San Diego, Plural Publishing.

Van Dyk, A. (2005). HIVIAIDS Care and Counselling, A Multidisciplinary Approach. Cape Town, South Africa, Pearson Education.

Van Kooten Niekerk, N.K.M, Knies, M., Howard, J., Rabie, H., Zeier, M., van Rensburg, A., Frans, N., Schaaf, H.S., Fatti, G., Little, F., \& Cotton, M.F. (2005). 
The first 5 years of the family clinic for HIV at Tygerberg Hospital: Family demographics, survival of children and early impact of antiretroviral therapy. Journal of Tropical Paediatrics 52(1), pp. 3-11.

WHO (2005). Interim WHO Clinical staging of HIVIAIDS and HIVIAIDS Case Definitions for Surveillance. www.who.int/hiv/pub/guidelines/clinicalstaging.pdf 


\section{Appendix 1}

$\begin{array}{ll}\text { V7 } & \text { HAART } \\ \text { V8 } & \text { Treatment start date } \\ \text { V9 } & \text { Treat-Mn } \\ \text { V10 } & \% \text { CD4 } \\ \text { V11 } & \text { Bacterial } \\ \text { V12 } & \text { Viral } \\ \text { V13 } & \text { Fungal } \\ \text { V14 } & \text { Myco } \\ \text { V15 } & \text { Lung } \\ \text { V16 } & \text { Malig } \\ \text { V17 } & \text { Other }\end{array}$

1 = Yes, 2 = No, 3 = Pending

ddlmmlyy

$\mathrm{nn}$

nn.nn

$1=$ Strep pneum, $2=$ Haemo infl, $3=$ Klebs pneum, $4=$ Salm spp, $5=$ Esch coli, $6=$ Staph aur, $7=3+6$

$1=$ RSV, $2=$ Hum metpn, $3=$ Adenov, $4=$ Influ, $5=$ Parainflu, $6=\mathrm{CMV}, 7-$ ? = combinations

$1=$ PCP, 2 = Candida, $3=1+2$

$1=$ MycoTB, 2 = Non-TB Myco, 3 = BCG, 4- = combinations

$1=$ LIP, 2 = N-SpIntst, $3=1+2$

$1=$ Kaposi, 2 = Lymph, 3 = Leiom, 4-? = combinations

1 = Chronic Lung, 2 = Bronchie, $3=$ RAirways, $4=$ Reflux, $5=$ Cardiomyop, $6=$ Retinitis, $7=$ Hepatitis,

$8=$ Colitis, $9=$ Oesophag, $10=$ Hsimplex, $11=$ Var zoster,

$12=$ Chickenpox, $13=$ Mollusc cont, $14=\mathrm{HPV}, 15=\mathrm{PML}, 16=$ Crypto, $17=$ Meningitis, $18=\mathrm{TBM}$,

$19=$ Toxoplas, $20=\mathrm{IRIS}, 21=$ Herpes Zoster

V18 Candida

$1=$ Oral, $2=$ Laryng, $3=$ Oesoph, $4=$ Dissem, $5=1+3$

V19 Enceph

1 = Static, 2 = Progressive

$1=$ Yes, $2=$ No, $3=$ Pending

V20 Seizures

1 = Spas dia, 2 = Spas quad, $3=$ Pseudo palsy, $4=$ Dystonia, $5=$ Tremors, $6=$ Ataxia, 7 = Focal

V22 Behav

V23 Cognit

$1=\mathrm{ADD}, 2$ = Asnxiety, $3=\mathrm{ODD}, 4=$ Conduct, $5-$ ? = combinations

1 = Learn diff, 2 = Red Cog Score, $3=1+2$

V24 Renal

$1=$ Yes, $0=$ No

V25 UTI

$1=$ Yes, $0=$ No

V26 Exp-Lang

$1=$ Ref cry, $2=$ Cooing, $3=$ Vocal play, $4=$ Jargon, $5=$ One word, $6=2$ to 3 words, $7=$ Short phrases,

$8=$ Simple sentence, 9 = Complex sentence

V27 Comm-Dis

1 = Acute OM \& eff, 2 = Acute OM \& No eff, 3 = Hear impair, 4 = Chronic OM, 5- = combinations

V28 Dev-Phon

$1=$ Fronting, $2=$ Conson del, $3=$ Cluster red, $4=$ Stopping, $5=$ Backing, $6=$ Gliding, $7=$ Denasdal,

8 = Substitutions, 9- = combinations

V29 Feed

V30 Swallow

$1=$ Poor ROM, 2 = Weak suck, 3 = Poor coords, 4 = Poor latch, 5-? = combinationa

$1=$ Yes, $0=$ No

$1=$ Yes, $0=$ No

$1=\mathrm{DD}, 2=$ Voice disorder, $3=$ Dysarthr, 4- ? = combinations

V32 Speech

V33 Referral

$1=\mathrm{SLT}, 2=$ Physio, $3=\mathrm{OT}, 4=$ Diet, $5=$ Soc Worker, $6=$ Psycho, $7=4+5,8=3+4+5,9=4+2$, $10=1+3+5$

V34 Team

$1=$ Multi, $2=$ Inter, $3=$ Trans, $4=$ Unclear 


\section{Appendix 2: WHO (2005) Clinical staging of HIVIAIDS in infants and children}

Stage $I$

- Asymptomatic

- Persistent Generalized Lymphadenopathy (PGL)

\section{Stage II}

- Hepatosplenomegaly

- Papular pruritic eruptions, Seborrhoeic dermatitis

- Extensive human papilloma virus infection, Molluscum contagiosum

- Herpes zoster

- Fungal nail infections

- Parotid enlargement

- Recurrent oral ulcerations, Lineal gingival erythema (LGE), Angular cheilitis

- Recurrent or chronic RTIs (otitis media, otorrhoea, sinusitis)

\section{Stage III}

Conditions where a presumptive diagnosis can be made on the basis of clinical signs or simple investigations

- Moderate unexplained malnutrition (between the 3rd percentile and $60 \%$ of expected weight)

- Unexplained persistent diarrhoea (14 days or more)

- Unexplained persistent fever (intermittent or constant, for longer than one month)

- Oral candidiasis (outside neonatal period)

- Oral hairy leukoplakia, Acute necrotizing ulcerative gingivitis/periodontitis

- Severe recurrent presumed bacterial pneumonia

- Pulmonary TB

Conditions where confirmatory diagnostic testing is necessary

- Chronic HIV-associated lung disease, including brochiectasis

- Lymphoid interstitial pneumonitis (LIP)

- Unexplained anaemia $(<8 \mathrm{~g} / \mathrm{dl})$, and or neutropenia $\left(<1000 / \mathrm{mm}^{3}\right)$ and or thrombocytopenia $\left(<50000 / \mathrm{mm}^{3}\right)$ for more than one month

\section{Stage IV}

Conditions where a presumptive diagnosis can be made on the basis of clinical signs or simple investigations

- Unexplained severe wasting or severe malnutrition

- Pneumocystis pneumonia

- Extrapulmonary TB

- Oesophageal candidiasis

- Recurrent severe presumed bacterial infections (excluding pneumonia)

- Chronic herpes simplex infection (orolabial or cutaneous of more than one month duration)

- Kaposi's sarcoma

- CNS toxoplasmosis (outside the neonatal period)

- HIV-associated encephalopathy

Conditions where confirmatory diagnostic testing is necessary

- CMV infection (CMV retinitis or infection of organs other than liver, spleen or lymph nodes; onset at age one month or more)

- Extrapulmonary cryptococcosis including meningitis

- Any disseminated endemic mycosis

- Cryptosporidiosis, Isosporiasis

- Disseminated non-tuberculous mycobacteria infection

- Candida of trachea, bronchi or lungs

- Visceral herpes simplex infection

- Acquired HIV-associated rectal fistula

- Cerebral or B cell non-Hodgkin's lymphoma

- Progressive multifocal leukoencephalopathy (PML)

- HIV-associated cardiomyopathy or nephropathy 


\section{Appendix 3: questionnaire}

Please answer all the question by circling the appropriate option or by writing your answer in the space provided:

1. What is your gender?
a. Male
b. Female

2. What is your ethnicity?
a. White
b. Black
c. Indian
d. Coloured
e. Other: please specify

3. What is your age? (in completed years):

4. How many years' experience do you have in working with the paediatric HIV/AIDS population? (please answer in months):

5. For how long have you been working with the paediatric HIVIAIDS population at this outreach clinic?

6. What do you feel is your primary role when working with the paediatric HIVIAIDS population?

7. On average how long do you spend with a child on an initial assessment? (please answer in minutes):

8. On average how long is spent per child per follow up visit? (please answer in minutes):

9. Are you on the lookout for paediatric HIVIAIDS patients what you are working with that present with general developmental delay?
a. Yes
b. No

10. Have you observed that the paediatric HIVIAIDS population with whom you are working with presents with general developmental delay?
a. Never
b. Sometimes
c. Often
d. Always

11. Does the problem of general developmental delay occur more often in the patients coming to the clinic compared to the general population?
a. Less of a problem
b. The same
c. More of a problem

12. What do you think is the most likely reason for a child with HIVIAIDS to present with developmental delay?

13. Are you on the lookout for paediatric HIVIAIDS patients that you are working with who present with delays in language development?

a. Yes

b. No

14. Have you observed that the paediatric HIVIAIDS population with whom you are working with presents with delays in language development?
a. Never
b. Sometimes
c. Often
d. Always

15. Does the problem of delays in language development occur more often in the patients coming to the clinic compared to the general population?
a. Less of a problem
b. The same
c. More of a problem

16. What do you think is the most likely reason for a child with HIVIAIDS to present with delays in language development?

17. Are you on the lookout for paediatric HIVIAIDS patients that you are working with who present with cognitive difficulties?
a. Yes

b. No

18. Have you observed that the paediatric HIVIAIDS population with whom you are working with presents with cognitive difficulties?
a. Never
b. Sometimes
c. Often
d. Always 
19. Does the problem of cognitive difficulties occur more often in the patients coming to the clinic compared to the general population?

a. Less of a problem

b. The same

c. More of a problem

20. What do you think is the most likely reason for a child with HIVIAIDS to present with cognitive difficulties?

21. Are you on the lookout for paediatric HIVIAIDS patients that you are working with who present with feeding and/or swallowing difficulties?

a. Yes

b. No

22. Have you observed that the paediatric HIVIAIDS population with whom you are working with presents with feeding and/or swallowing difficulties?

a. Never

b. Sometimes

c. Often

d. Always

23. Does the problem of feeding and/or swallowing difficulties occur more often in the patients coming to the clinic compared to the general population?

a. Less of a problem

b. The same

c. More of a problem

24. What do you think is the most likely reason for a child with HIVIAIDS to present with feeding and/or swallowing difficulties?

25. Do you feel that the paediatric HIVIAIDS population with whom you are working with requires speech-language therapy?
a. Never
b. Sometimes
c. Often
d. Always

26. Do you feel that the paediatric HIVIAIDS population with whom you are working with would benefit from speech-language therapy?
a. Never
b. Sometimes
c. Often
d. Always

27. Do you feel that the paediatric HIVIAIDS population with whom you are working with requires audiological intervention?
a. Never
b. Sometimes
c. Often
d. Always

28. Do you feel that the paediatric HIVIAIDS population with whom you are working with would benefit from audiological intervention?
a. Never
b. Sometimes
c. Often
d. Always

29. Do you feel that the paediatric HIVIAIDS population with whom you are working with would benefit from a multidisciplinary approach to intervention?
a. Never
b. Sometimes
c. Often
d. Always

30. In your opinion, are doctors adequately trained in identifying those children who require referrals to other professionals?
a. Never
b. Sometimes
c. Often
d. Always

31. In your opinion, are doctors sufficiently aware of the impact that delays in assessing delays of general development may have on paediatric HIVIAIDS patients coming to the clinic?
a. Never
b. Sometimes
c. Often
d. Always 
32. In your opinion, are doctors sufficiently aware of the impact that delays in assessing delays in language development may have on paediatric HIVIAIDS patients coming to the clinic?
a. Never
b. Sometimes
c. Often
d. Always

33. In your opinion, are doctors sufficiently aware of the impact that delays in assessing delays in cognitive difficulties may have on paediatric HIVIAIDS patients coming to the clinic?
a. Never
b. Sometimes
c. Often
d. Always

34. In your opinion, are doctors sufficiently aware of the impact that delays in assessing delays in feeding and/or swallowing may have on paediatric HIVIAIDS patients coming to the clinic?
a. Never
b. Sometimes
c. Often
d. Always

Thank you for your co-operation in answering the above questions. 